\title{
Erratum to: Gln50Ter Polymorphism of Fc $\gamma$ receptor IIB gene associated with genetic susceptibility to human systemic lupus erythematosus in Chinese populations
}

Faming Pan $\cdot$ Dongqing Ye $\cdot$ Kechun Zhang $\cdot$

Xiangpei $\mathrm{Li} \cdot$ Jianhua $\mathrm{Xu} \cdot$ Hong Chen

Published online: 25 November 2010

(C) Springer-Verlag 2010

Erratum to: Arch Dermatol Res (2007) 299:47-51

DOI 10.1007/s00403-006-0732-7

This article has been retracted because of duplicate publication of the same data in different journals.

The online version of the original article can be found under doi:10.1007/s00403-006-0732-7.

F. Pan $\cdot$ D. Ye $(\bowtie) \cdot$ K. Zhang $\cdot$ H. Chen Department of Epidemiology and Biostatistics,

School of Public Health, Anhui Medical University,

Hefei, Hefei, Anhui 230032, China

e-mail: ydq@ahmu.edu.cn

X. Li

Department of Rheumatology, Anhui Provincial Hospital,

Hefei 230000, China

J. Xu

Department of Rheumatology, First Affiliated Hospital,

Anhui Medical University, Hefei 230032, China 